ORIGINAL ARTICLE

\title{
Renal tubular dysfunction in children living in the Aral Sea Region
}

\author{
K Kaneko, M Chiba, M Hashizume, O Kunii, S Sasaki, T Shimoda, Y Yamashiro, W Caypil, \\ D Dauletbaev
}

See end of article for authors' affiliations

.....................

Correspondence to: Dr KKaneko, Department of Pediatrics, Juntendo University School of Medicine, 2-1-1 Hongo, Bunkyo-ku, Tokyo 113 8421, Japan; kkaneko@ med.juntendo.ac.jp

Accepted 4 March 2003
Background: The Aral Sea region is a natural area seriously polluted by human activities. Recent surveillance revealed the increased prevalence of diverse chronic diseases in children.

Aims: To investigate the function of renal tubules, which are most at risk of damage as a result of heavy metal intoxication, in children of the Aral Sea region.

Methods: A group of 205 children living in Kazalinsk, close to the Aral Sea, and a group of 187 children living in Zhanakorgan, far from the Aral Sea, were examined by means of random urine samples. Both urinary $\mathrm{N}$-acetyl- $\beta$-o-glucosaminidase (NAG; $\mathrm{U} / \mathrm{mmol} \mathrm{Cr}$ ) and $\beta_{2}$ microglobulin (BMG; $\mu \mathrm{g} / \mathrm{mmol} \mathrm{Cr}$ ) were calculated for each subject.

Results: Mean urinary NAG and BMG were both significantly higher in Kazalinsk than in Zhanakorgan (NAG: 0.77 (0.58) and 0.62 (0.37) U/mmol Cr; BMG: 41.8 (54.8) and $22.5(20.4) \mu \mathrm{g} / \mathrm{mmol} \mathrm{Cr}$, respectively; mean (SD), $p<0.01)$. The number of children with abnormal values of NAG $(>1.5 \mathrm{U} / \mathrm{mmol}$ $\mathrm{Cr}$ ) was significantly more prevalent in Kazalinsk than in Zhanakorgan $7.9 \%$ and $2.6 \%$, respectively, $\mathrm{p}<0.05)$.

Conclusion: Renal tubular function of children around the Aral Sea region is profoundly impaired. This should be taken into account when considering the health problems of this area.
$\mathrm{T}$ he Aral Sea area, which includes the Republic of Karakalpakstan (Uzbekistan), Kzylorda district (Kazakhstan), and Dashovuz district (Turkmenistan), is a natural area seriously polluted by human activities (fig l). The irrigation of cotton and rice fields using river water from the Amu-Darya and the Syr-Darya, has caused a decline in the area of the Aral sea bed from 64500 to $30000 \mathrm{~km}^{2}$, and the heavy application of insecticides, pesticides, herbicides, and defoliants since the 1960s has created a hazardous situation for the health of approximately 3.5 million people living in this area. ${ }^{1}$

It has been postulated that people are exposed to various toxic chemicals, such as polychlorinated biphenyl (PCB) pesticides, and to heavy metals like lead $(\mathrm{Pb})$ and cadmium (Cd). ${ }^{1-3}$ The impact of exposure to these environmental pollutants on human health is only beginning to emerge; in parallel with the worsening ecological situation, rates of diseases among children are increasing. Furthermore, the incidence and prevalence of tuberculosis, malignancies, psychiatric disease, and alcoholism are reported to be increasing. ${ }^{2}$

As chronic intoxication of heavy metals is known to cause renal tubular injury, ${ }^{4-7}$ we hypothesised that renal tubular function might be deteriorating in children living in this area. This study was undertaken to clarify the prevalence of renal tubular dysfunction in children living in the Aral Sea region.

\section{SUBJECTS AND METHODS}

For collection of urine samples, we selected nine villages located at the mouth of the Syr-Darya River in Kazalinsk as an area close to the Aral Sea (within $200 \mathrm{~km}$ ). In addition, sampling from children living in the four villages in Zhanakorgan, selected as a control area (nearly $500 \mathrm{~km}$ distant from Kazalinsk area), was also performed.

Urine samples of school age children born between 1985 and 1993 (6-15 years of age) were chosen from the list of children at the selected health centres. An equal number of boys and girls were randomly selected according to the year of birth. Parents or guardians living with eligible children were invited to come to the health centre on a designated day with their children for collection of health data; local nurses of public hospitals interviewed mothers or guardians of children at the health centres using the questionnaire cards in Kazakh language. According to this questionnaire, more than $90 \%$ of children had good health status, with no interdistrict differences, although the percentage of recent gastrointestinal symptoms such as diarrhoea and abdominal pain was significantly higher among children in Kazalinsk than in Zhanakorgan (diarrhoea $11.3 \%$ v 5.6\%; abdominal pain $8.1 \%$ v 3.9\%; p < 0.05).

Written informed consent was obtained from parents or guardians. This study was approved by the institutional review board (acceptance no. 62 of the ethical committee at Juntendo University School of Medicine).

A total of 392 random urine samples were collected from the children who were on a non-restricted diet and visited the health centre in either Kazalinsk or Zhanakorgan on the day of the survey (in August 2000). Urine samples were frozen at $-20^{\circ} \mathrm{C}$ within six hours after sampling and kept until analysis of $\mathrm{N}$-acetyl- $\beta$-D-glucosaminidase (NAG) and $\beta_{2}$ microglobulin (BMG); the former is an enzyme, the urinary concentration of which increases in renal tubular cell injury, and the latter is a low molecular weight protein which increases when its reabsorption by renal tubular cells is disturbed. Urinary concentrations of NAG and BMG were measured by the MCP-NAG method and immunoassay, respectively. Creatinine $(\mathrm{Cr})$ was also measured by the creatinase method

Abbreviations: BMG, $\beta 2$ microglobulin; $\mathrm{Cr}$, creatinine; NAG, N-acetyl$\beta$-D-glucosaminidase; PCB, polychlorinated biphenyl 


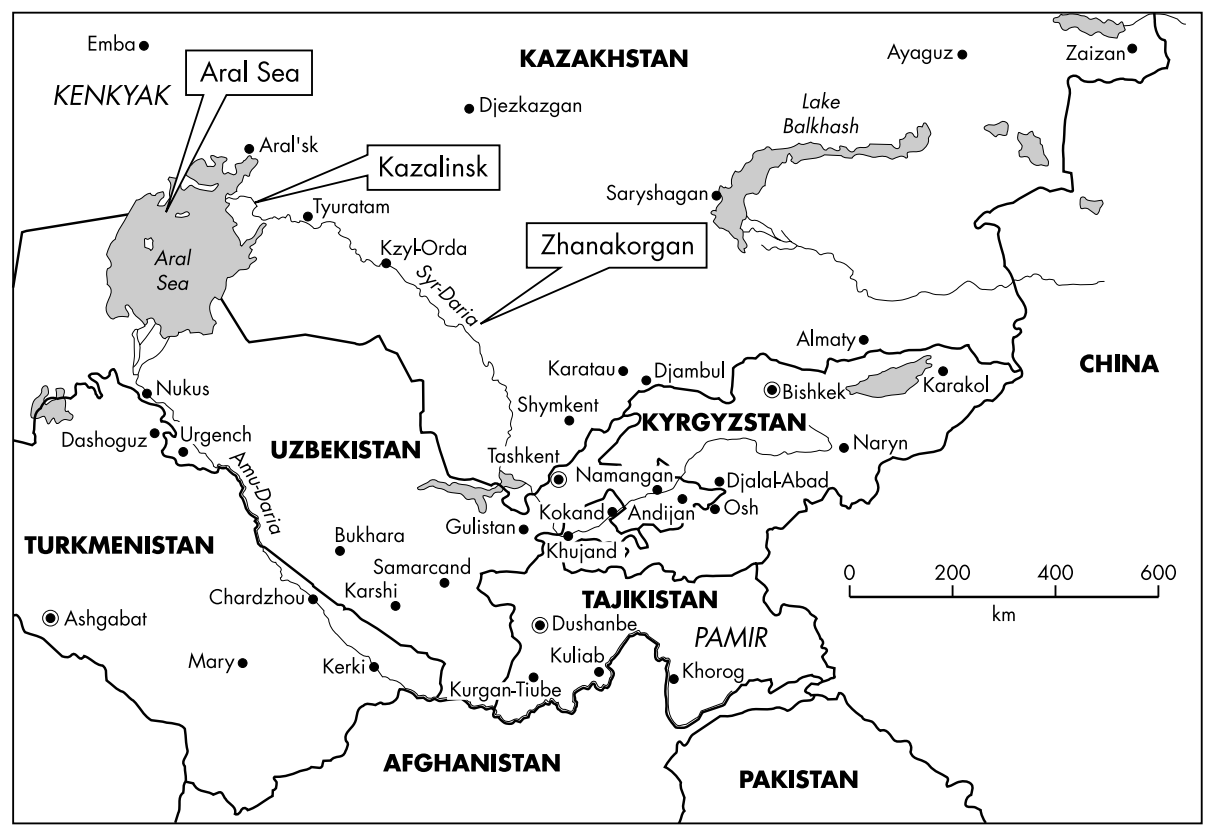

Figure 1 Study areas in Republic of Kazakhstan.

for calculation of the ratios of urine NAG per creatinine $(\mathrm{U} / \mathrm{mmol} \mathrm{Cr})$, and BMG per creatinine $(\mu \mathrm{g} / \mathrm{mmol} \mathrm{Cr})$.

\section{Statistical analysis}

Results were expressed as mean (SD). As the groups of data were distributed parametrically, statistical analyses were performed using Student's $t$ test (two tailed analysis) for comparison between the groups. A $\chi^{2}$ test with Yates's correction was also applied for the comparison of prevalence between the groups. A p value less than 0.05 was regarded as significant.

\section{RESULTS}

\section{Distribution of age and health data}

Of 392 urine samples, 203 were obtained from children of the Kazalinsk region (103 boys, 100 girls; mean age 10.6 (2.5) years) and 189 from children of the Zhanakorgan region (102 boys, 87 girls; mean age 11.1 (2.7) years). There were no significant differences in the distribution of age between these two regions.

\section{Differences between regions in urinary excretions of NAG and BMG}

The mean urinary NAG concentration corrected by creatinine (U/mmol Cr) was significantly higher in children living in Kazalinsk than that in children living in Zhanakorgan (see fig 2); mean (SD) values were 0.77 (0.58) and 0.62 (0.37), respectively $(\mathrm{p}<0.01)$. Similarly, there was a significant difference in urinary BMG concentration corrected by creatinine $(\mu \mathrm{g} / \mathrm{mmol} \mathrm{Cr})$ between children of Kazalinsk and those of Zhanakorgan (fig 2); mean (SD) values were 41.8 (54.8) and 22.5 (20.4), respectively $(\mathrm{p}<0.01)$.

\section{Prevalence of renal tubular enzymuria and proteinuria}

The number of children with abnormal NAG $(>1.5 \mathrm{U} / \mathrm{mmol}$ $\left.\mathrm{Cr}^{8}\right)$ was significantly more prevalent in Kazalinsk than in Zhanakorgan: 16 of 203 children (7.9\%) and 5 of 189 children $(2.6 \%)$, respectively ( $p<0.05$; table 1$)$. However, there was no significant difference in the number of children with abnormal BMG $\left(>5.94 \mu \mathrm{g} / \mathrm{mmol} \mathrm{Cr}^{9}\right)$ between the regions: 185 of 203 children $(91.1 \%)$ in Kazalinsk and 172 of 189 children $(91.0 \%)$ in Zhanakorgan $(\mathrm{p}>0.05)$.

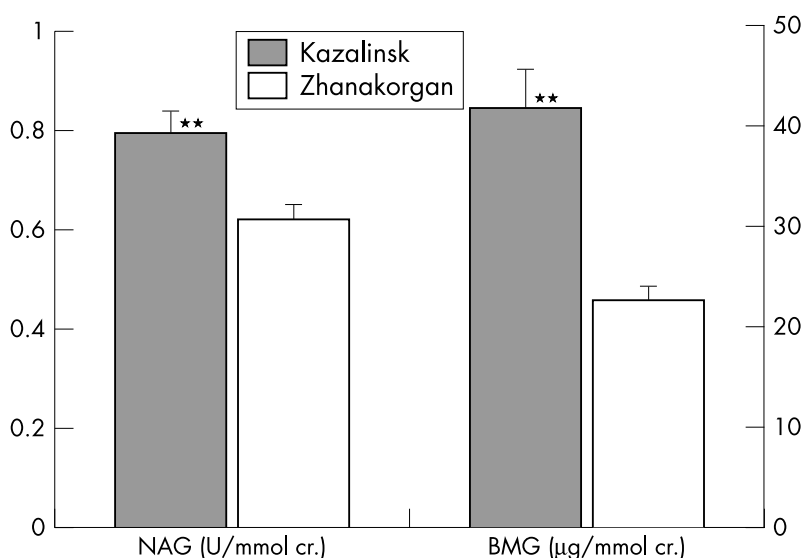

Figure 2 Mean urinary BMG $(\mu \mathrm{g} / \mathrm{mmol}$ creatinine) and NAG $(\mathrm{U} / \mathrm{mmol}$ creatinine) of children of the Aral Sea region (Kazalinsk) and the control region (Zhanakorgan). Error bars indicate SEM. ${ }^{* *} p<0.01$ (difference between regions).

\section{DISCUSSION}

The deterioration of health among people living in the Aral Sea region in particular has caused much concern and is generally considered to have multifactorial backgrounds. ${ }^{2}$ One obvious factor is the impoverishment of the people, resulting in poor nutrition and sanitation. ${ }^{10}$ Another is the fact that people are exposed to various toxic chemicals, such as PCB pesticides, and to heavy metals like $\mathrm{Pb}$ and $\mathrm{Cd}^{1-3}$ The way by which the population is exposed is generally thought to be from the air, from drinking water, and from various food products. ${ }^{2}$

There have been numerous reports regarding the high frequency of delayed growth and puberty of children and increasing infant mortality rate in this area. ${ }^{211}$ It was recently reported that children who lived near the waste incinerators and were supposed to be chronically exposed to environmental pollutants, such as $\mathrm{Pb}$ and $\mathrm{Cd}$, PCBs, dioxin-like compounds, and metabolites of volatile organic compounds matured sexually at an older age and testicular volume was smaller in boys than those lived in the control areas; in this study, biomarkers of glomerular or tubular renal dysfunction 
Table 1 Prevalence of renal tubulopathy in children living in the Aral Sea region

\begin{tabular}{|c|c|c|c|c|}
\hline & \multicolumn{2}{|l|}{ Urinary NAG* } & \multicolumn{2}{|l|}{ Urinary BMG* } \\
\hline & $\begin{array}{l}\text { Zhanacorgan } \\
\text { region }(n=189)\end{array}$ & $\begin{array}{l}\text { Kazalinsk } \\
\text { region }(n=203)\end{array}$ & $\begin{array}{l}\text { Zhanacorgan } \\
\text { region }(n=189)\end{array}$ & $\begin{array}{l}\text { Kazalinsk } \\
\text { region }(n=203)\end{array}$ \\
\hline $\begin{array}{l}\text { No. of children with abnormal values } \\
\text { Prevalence }(\%) \\
\text { p value ( } \chi^{2} \text { test with Yates's correction) }\end{array}$ & $\begin{array}{l}5 \\
2.6 \\
<0.05\end{array}$ & $\begin{array}{l}16 \\
7.9\end{array}$ & $\begin{array}{l}172 \\
91.0 \\
>0.05\end{array}$ & $\begin{array}{l}185 \\
91.1\end{array}$ \\
\hline
\end{tabular}

in individuals were positively correlated with blood Pb levels. ${ }^{9}$ Thus the kidney is one of the most vulnerable organs to various toxic compounds because many xenobiotic substances are excreted through urine. Our study was therefore conducted to investigate the renal tubular function of children living in the Aral Sea region, which might be impaired due to the ecological deterioration.

In order to clarify the influence of ecological factors and to exclude other factors that may affect the urinary concentrations of NAG and BMG, we adjusted the race, age, and sex between the groups. The only difference is the distance from the Aral Sea-that is, Kazalinsk is about $500 \mathrm{~km}$ closer to the Aral Sea than Zhanakorgan (fig 1).

The results clearly showed that the prevalence of children with renal tubular dysfunction was extremely high in children around the Aral Sea. This is, to the best of our knowledge, the first report to suggest that renal tubular dysfunction should be taken into account when considering health problems in this area.

Although the reason for renal tubular dysfunction of children in this area is currently unknown, it is possible that children around the area are exposed to various toxic chemicals, such as heavy metals like $\mathrm{Pb}$ and $\mathrm{Cd}{ }^{2}$ widely known to be toxic enough to damage human renal tubules. In our analytical results, however, concentrations of $\mathrm{Pb}$ and Cd were not high in urine, blood, and hair specimens in these subjects. Therefore, other causes might be considered. Uranium is known to be one of the factors which cause renal tubular dysfunction, assessed by increased levels of urinary NAG and BMG. ${ }^{56}$ We are now investigating the possibility of uranium as a cause of renal dysfunction.

Furthermore, we postulated that hypercalciuria was more prevalent in Kazalinsk than in Zhanakorgan. ${ }^{12}$ A recent study has revealed that hypercalciuria may reflect renal tubular damage caused by Cd because it can impair the uptake of calcium by tubular cells. ${ }^{7}$

From these findings, we consider that the high prevalence of renal tubular dysfunction in children around the Aral Sea is due to exposure to a considerable amount of toxic substances contained in the air, drinking water, and various food products in this area.

In conclusion, renal tubular function in children living in the Aral Sea region is severely impaired. As impaired renal tubular function in children can be associated with stunted growth, renal tubular function should be taken into account when considering the health problems of this area.

\section{ACKNOWLEDGEMENTS}

The authors thank Dr Amangeldi Kadirbaev and Dr Saken Alseyt, Regional Health Authorities, and Dr Z Mazhitova, National
Children's Rehabilitation Center "URPAK", Kazakhstan for their cooperation. This study was supported by a grant from the Toyota Foundation.

\section{Authors' affiliations}

K Kaneko, Y Yamashiro, Department of Pediatrics, Juntendo University School of Medicine, Tokyo, Japan

M Chiba, Department of Epidemiology and Environmental Health, Juntendo University School of Medicine, Tokyo, Japan

M Hashizume, O Kunii, Department of International Community Health, Graduate School of Medicine, The University of Tokyo, Tokyo, Japan

S Sasaki, Scientific evaluation of Dietary Reference Intakes, National Institute of Health and Nutrition, Tokyo, Japan

T Shimoda, Faculty of Home Economics, Kyushu Women's University, Kitakyushu, Japan

W Caypil, Department of Biochemistry, Kazakh State Medical University, Kazakhstan

D Dauletbaev, Ministry of Health, Kzyl-Orda, Kazakhstan, Kazakhstan

\section{REFERENCES}

1 Ataniyazova OA, Baumann RA, Liem AK, et al. Levels of certain metals, organochlorine pesticides and dioxins in cord blood, maternal blood, human milk and some commonly used nutrients in the surroundings of the Aral Sea (Karakalpakstan, Republic of Uzbekistan). Acta Paediatr $2001 ; 90: 801-8$

2 Jensen S, Mazhitova Z, Zetterstrom R. Environmental pollution and child health in the Aral Sea region in Kazakhstan. Sci Total Environ 1997; 206: 187-93.

3 Mazhitova Z, Jensen S, Ritzen M, et al. Chlorinated contaminants, growth and thyroid function in schoolchildren from the Aral Sea region in Kazakhstan. Acta Paediatr 1998;87:991-5.

4 Liv CS, Kuo HW, Lai JS, et al. Urinary N-acetyl-beta-glucosaminidase as an indicator of renal dysfunction in electroplating workers. Int Arch Occup Environ Health 1998;71:348-52.

5 Noonan CW, Sarasua SM, Campagna D, et al. Effects of exposure to low levels of environmental cadmium on renal biomarkers. Environ Health Perspect 2002;110:151-5.

6 Zamora ML, Tracy BL, Zielinski JM, et al. Chronic ingestion of uranium in drinking water: a study of kidney bioeffects in humans. Toxicol Sci 1998;43:68-77.

7 Wu X, Jin T, Wang Z, et al. Urinary calcium as a biomarker of renal dysfunction in a general population exposed to cadmium. J Occup Environ Med $2001 ; 43: 898-904$.

8 Nishida $M$, Kawakatsu $H$, Komatsu $H$, et al. Values for urinary beta 2-microglobulin and $\mathrm{N}$-acetyl-beta-D-glucosaminidase in normal healthy infants. Acta Paediatr Jpn 1998;40:424-6.

9 Staessen JA, Nawrot T, Hond ED, et al. Renal function, cytogenetic measurements, and sexual development in adolescents in relation to environmental pollutants: a feasibility study of biomarkers. Lancet 2001;357:1660-9.

10 Stone R. Coming to grips with the Aral Sea's grim legacy. Science 1999;284:30-3.

11 Zetterstrom R. Food pollutants and child health with special reference to the situation in the Aral Sea region in Kazakhstan. Scand J Nutr 1998;42:130-5.

12 Kaneko K, Chiba M, Hashizume M, et al. Extremely high prevalence of hypercalciuria in children living in the Aral Sea Region. Acta Paediatr 2002;91:1116-20. 